\title{
Continuous renal replacement therapy in patients with HIV/AIDS
}

\author{
Hebing Guo ${ }^{\dagger}$, Jingyuan Liư, Lin Pu, Jingjing Hao, Ningning Yin, Yufeng Liu, Haofeng Xiong and Ang Li*
}

\begin{abstract}
Background: Acute kidney injury (AKI) is a common complication among human immunodeficiency virus (HIV)infected patients resulting in increased morbidity and mortality. Continuous renal replacement therapy (CRRT) is a useful method and instrument in critically ill patients with fluid overload and metabolic disarray, especially in those who are unable to tolerate the intermittent hemodialysis. However, the epidemiology, influence factors of CRRT and mortality in patients with HIV/AIDS are still unclear in China. This study aims to study the HIV-infected patients admitted in Intensive Care Unit (ICU) and explore the influence factors correlated with CRRT and their prognosis.

Methods: We performed a retrospective case-control study in the ICU of the Beijing Ditan Hospital Capital Medical University. From June 1, 2005 to May 31, 2017, 225 cases were enrolled in this clinical study.

Results: 122 (54.2\%) patients were diagnosed with AKI during their stay in ICU, the number and percentage of AKI stage 1, 2 and 3 were 38 (31.1\%), 21(17.2\%) and 63(51.7\%), respectively. 26.2\% of AKI patients received CRRT during the stay of ICU. 56.25\% CRRT patients died in ICU. The 28-day mortality was 62.5\%, and the 90-day mortality was $75 \%$. By univariate logistics analysis, it showed that higher likelihood of diagnosis for respiratory failure $(\mathrm{OR}=7.333$, $95 \% \mathrm{Cl} 1.467-36.664, p=0.015)$, higher likelihood of diagnosis for septic shock $(\mathrm{OR}=1.005,95 \% \mathrm{Cl} 1.001-1.01, p=0.018)$, and higher likelihood to use vasoactive agents $(\mathrm{OR}=10.667,95 \% \mathrm{Cl} 1.743-65.271, p=0.001)$, longer mechanical ventilation duration ( $\mathrm{OR}=1.011,95 \% \mathrm{Cl} 1.002-1.019, p=0.011)$, higher likelihood for diagnosis for $\mathrm{PCP}(\mathrm{OR}=7.50,95 \% \mathrm{Cl}$ 1.288-43.687, $p=0.025)$, higher SOFA score at ICU admission (OR $=1.183,95 \% \mathrm{Cl} 1.012-1.383, p=0.035)$, longer duration of CRRT (OR= $1.014,95 \% \mathrm{Cl} 1.001-1.028, p=0.034)$ contributed to a higher mortality at ICU. The Cox Analysis for the cumulative survival of AKI 3 patients between the CRRT and non-CRRT groups shows no significant differences ( $p=0.595)$.
\end{abstract}

Conclusions: There is a high incidence of AKI in HIV-infected patients admitted in our ICU. Patients with severe AKI were more prone to be admitted for CRRT and have a consequent poor prognosis.

Keywords: HIV/AIDS, CRRT, Mortality, Risk factors

\section{Introduction}

Acute kidney injury (AKI) is a common disease in critical patients and affects more than 13 million people all around the world annually [1]. Patients who are infected by human immunodeficiency virus (HIV) are more vulnerable to suffer from AKI and showing a higher mortality and morbidity

\footnotetext{
* Correspondence: dtyyicu@163.com

${ }^{\dagger}$ Hebing Guo and Jingyuan Liu contributed equally to this work. Department of Critical Care Medicine, Beijing Ditan Hospital, Capital Medical University, No. 8 Jingshundong Street, Beijing 100015, Chaoyang District, China
}

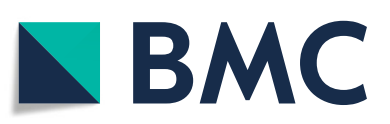

(c) The Author(s). 2020 Open Access This article is licensed under a Creative Commons Attribution 4.0 International License, which permits use, sharing, adaptation, distribution and reproduction in any medium or format, as long as you give appropriate credit to the original author(s) and the source, provide a link to the Creative Commons licence, and indicate if changes were made. The images or other third party material in this article are included in the article's Creative Commons licence, unless indicated otherwise in a credit line to the material. If material is not included in the article's Creative Commons licence and your intended use is not permitted by statutory regulation or exceeds the permitted use, you will need to obtain permission directly from the copyright holder. To view a copy of this licence, visit http://creativecommons.org/licenses/by/4.0/. The Creative Commons Public Domain Dedication waiver (http://creativecommons.org/publicdomain/zero/1.0/) applies to the data made available in this article, unless otherwise stated in a credit line to the data.
[2, 3]. 66\% HIV-infected patients are diagnosed with AKI during their stay in the Intensive Care Unit (ICU) [4]. Continuous renal replacement therapy (CRRT) has been an important maintenance intervention in patients with severe AKI for more than one decade $[5,6]$. However, few studies have clarified CRRT in patients with HIV/AIDS. Epidemiology and influence factors of CRRT in patients with HIV/ AIDS are still unclear in China. This study aims to make these determinations among HIV-infected individuals in an observational retrospective clinical study. 


\section{Methods}

\section{Study design and population}

The study is a retrospective research in ICU of the Beijing Ditan Hospital Capital Medical University which is one of the top three hospital for infectious diseases. About five hundred patients were admitted in this general ICU and there were 20-bed ward for both medical and surgical patients each year. We reviewed the Hospital Information management System (HIS) from June 1, 2005 to May 31, 2017 in Beijing Ditan Hospital Capital Medical University for this study. All of the databases were recorded and analyzed by infectiology specialists from our team. Patients who were clearly diagnosed with HIV and older than 18 years old were included in this study. Patients who underwent RRT before admission, stayed in ICU less than $48 \mathrm{~h}$ and were admitted in ICU more than once within 6 months, were excluded from this research. This study only recorded the first admission for patients who were admitted at ICU more than once within 6 months.

There were 284 cases admitted at ICU of Beijing Ditan Hospital Capital Medical University from June 1, 2005 to May 31, 2017. Forty seven cases were excluded because of the length of stay at ICU less than $48 \mathrm{~h}$. Four cases were excluded by accepting renal replacement therapy before admission. Meanwhile 8 patients were recorded the first admission because of admitting at ICU twice within 6 months. A total of 225 cases were considered for this study.

No trial of any specific therapeutic or prophylactic intervention was carried out and only observational data were used for our analysis. This study was approved by the Ethics Committee of Beijing Ditan Hospital, Capital Medical University, No. 2018-005-01.

\section{Definitions}

\section{AKI diagnosis}

We used the Kidney Disease Improving Global Outcomes (KDIGO) criteria for the diagnosis of AKI. As defined by the KDIGO, AKI would be diagnosed if there is a $50 \%$ rise in serum creatinine from baseline at any point during the patient's prior 7-day ICU admission; a rise in serum creatinine of $>26.5 \mathrm{mmol} / \mathrm{L}$ within a 48 -h period; a fall in urine output of $<0.5 \mathrm{~mL} / \mathrm{kg} / \mathrm{h}$ for more than $6 \mathrm{~h}$; an absolute serum creatinine of $>353.6 \mathrm{mmol} / \mathrm{L}$; or an RRT is initiated [7].

\section{HIV diagnosis}

As defined by the US Centers for Disease Control and Prevention (CDC) in a revised surveillance case definition for HIV infection in 2014, HIV infection is diagnosed when a positive result from HIV antibody or combination of an antigen/antibody test is obtained, and another positive result is obtained from a supplemental different HIV test, performed in parallel or subsequently to the initial test [8]. Alternatively, HIV infection is diagnosed if a positive result or report of a detectable quantity from any of the following HIV virologic tests has been obtained:

- Qualitative HIV NAT (DNA or RNA) - Quantitative HIV NAT (viral load assay)

- HIV-1 p24 antigen test

- HIV isolation (viral culture) or

- HIV nucleotide sequence (genotype) [9]

\section{Data collection}

The following demographic, clinical, laboratory data, complication and multiple organs support therapy were collected from the patient medical manuals and an electronic hospital database by four investigators (H. Guo, L. $\mathrm{Pu}$, J. Hao, and N. Yin): age, sex, body mass index, lymphocyte count, hemoglobin, albumin, t-bil, serum calcium, lactate, sodium bicarbonate, serum phosphate, Glomerular Filtration Rate (GRF), Mean Platelet Volume (MPV), Alanine Transaminase (ALT), glutamic oxalacetic transaminase (AST), Lactate Dehydrogenase (LDH), CD4 count at ICU admission, lowest CD4 count in ICU, Highly Active Anti-Retroviral Therapy (HAART), Pneumocystis Carinii Pneumonia (PCP), septic shock, respiratory failure, the use of vasoactive agents, duration of mechanical ventilation, duration of CRRT.

The severity of illness was evaluated by the Sequential Organ Failure Assessment (SOFA) and the Acute Physiology and Chronic Health Evaluation (APACHE)II score, which calculation was based on the worst variables recorded within the first $24 \mathrm{~h}$ of ICU admission.

All patients received CRRT through continuous venovenous hemodiafiltration (CVVHDF) (therapeutic dose of $30 \mathrm{ml} / \mathrm{kg}$ ) and the related data were not recorded in this study.

Length of ICU stay and hospital were recorded in the Electronic Hospital Database.

\section{Outcome measures}

Outcome was recorded by the HIS of Beijing Ditan Hospital Capital Medical University. Follow-up visit was conducted by infectious diseases specialists by telephone in this study.

\section{Statistical analysis}

Categorical variables were compared using a chi-squared test for trends. Risk factors were assessed by univariate analyses, and variables that were statistically significant $(p<0.05)$ in the univariate analyses were later included in a multivariate analysis. Univariate and multivariate analyses were performed using a logistic regression. The life table method was used to determine survival curves, 
and a Cox proportional hazards model was used to evaluate the statistical differences between the survival and non-survival curves. Data are presented as mean \pm standard deviation, median (interquartile range), percentage of number of cases, odds ratios (ORs) with $95 \%$ confidence intervals. A two-tailed $p<0.05$ was considered significant. Statistical analyses were performed using the SPSS version 22.0 software (SPSS, Inc., Chicago, IL).

\section{Results}

\section{Patients characteristics}

Among the 225 patients, 205 (91.1\%) were male. The average age of the total numbers was $42 \pm 13$ years. 122(54.2\%) patients were diagnosed with AKI during their stay at ICU. As shown in Fig. 1, the number and percentage of AKI stage $1 / 2 / 3$ were respectively 38 $(31.1 \%) / 21 \quad(17.2 \%) / 63$ (51.7\%). Thirty two patients (about $26.2 \%$ of total AKI) received continuous renal replacement therapy (CRRT) at ICU.56.25\% $(n=18)$ of patients who received CRRT died at ICU.
Comparison between AKI patients with CRRT and without are shown in Table 1. Hemoglobin and CD4 counts at ICU admission had a statistically significant difference ( $p=0.048$ and $p=0.043$, respectively). As per complications, the incidence of Pneumocystis carinii pneumonia (PCP) and respiratory failure showed a statistical significant difference $(p=0.006$ and $p=0.01$, respectively). In severity of illness, patients with CRRT were even worse both in SOFA and APACHE-II score $(p<0.001$, and $p<0.001$, respectively). Patients with CRRT stayed in the hospital for a shorter period than those without $(p=0.022)$.

As shown in Fig. 2, 9/13 patients (40.6\%) who were admitted at ICU for respiratory failure, died at ICU. Secondly, 2/10 patients (31.25\%) who received treatment at ICU mainly for AKI, died at ICU. Septic shock, intestinal perforation, cardiopulmonary arrest, central nervous system disease were the other factors for admission at ICU.

Table 2 shows the strength of association between death at ICU and its potential risk factors, was calculated by univariate logistics analysis. The result showed that

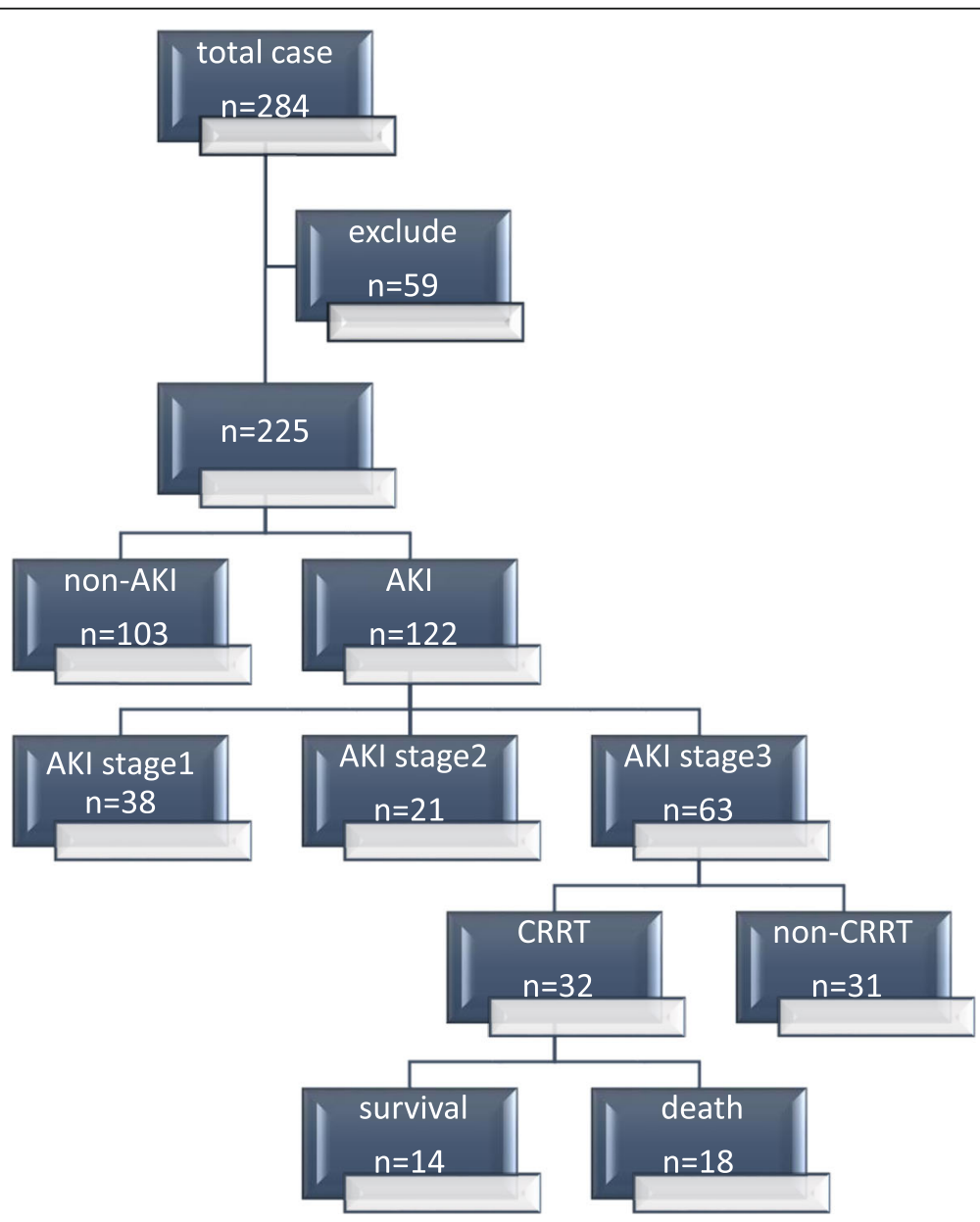

Fig. 1 Study flow chart detailing the inclusion and exclusion of patients 
Table 1 Demographic and Clinical Characteristics of 122 AKI Patients Admitted to the Intensive Care Unit

\begin{tabular}{|c|c|c|c|c|}
\hline & $\begin{array}{l}\text { Patients with AKI } \\
n=122\end{array}$ & $\begin{array}{l}\text { Patients with CRRT } \\
n=32\end{array}$ & $\begin{array}{l}\text { Patients without } \\
\text { CRRT } n=90\end{array}$ & $p$ \\
\hline Male(\%) & $112(91.8)$ & $31(96.9)$ & $81(90)$ & 0.452 \\
\hline Age(years) & $41(34-50)$ & $42(37-55.5)$ & $41(31-50)$ & 0.137 \\
\hline \multicolumn{5}{|l|}{ Blood routine and biochemical items } \\
\hline Lymphocyte count $\left(\times 10^{9}\right)$ & $0.5(0.3-0.92)$ & $0.54(0.34-1.10)$ & $0.5(0.30-0.80)$ & 0.205 \\
\hline Hemoglobin(g/L) & $98.9 \pm 27.4$ & $90.7 \pm 23.8$ & $101.8 \pm 28.1$ & 0.048 \\
\hline Albumin $(\mathrm{g} / \mathrm{L})$ & $28.0 \pm 5.8$ & $29.3 \pm 4.9$ & $27.5 \pm 6.1$ & 0.154 \\
\hline Total Bilirubin (u mol/L) & $8.65(5.38-13.43)$ & $7.75(5.03-15.33)$ & $9.15(5.4-13.43)$ & 0.682 \\
\hline Serum calcium(mmol/L) & $1.92(1.77-2.09)$ & $2.00(1.67-2.19)$ & $1.92(1.82-2.05)$ & 0.375 \\
\hline \multicolumn{5}{|l|}{ Items related to HIV infection } \\
\hline CD4 counts at ICU admission & $23(8-78)$ & $37(13-122)$ & $15(7-69)$ & 0.043 \\
\hline Patients with HAART & $30(24.6)$ & $11(34.4)$ & $19(21.1)$ & 0.135 \\
\hline \multicolumn{5}{|l|}{ Items related to $\mathrm{AKI}$} \\
\hline The first Creatinine in Hospital ( $\mathrm{u} \mathrm{mol} / \mathrm{L}) 72.7$ (54-129.3) & & $220.1(70.9-499.1)$ & $64.5(51.8-92.6)$ & $<0.001$ \\
\hline The highest Creatinine before in ICU(u mol/L)48.9 (34.7-70.8) & & $194.2(55.4-441.5)$ & $42.1(32.8-58.6)$ & $<0.001$ \\
\hline The highest Creatinine during ICU(u mol/L) 159.6 (85.6-331) & & $375.4(293.3-580.0)$ & $121.6(79.4-210.5)$ & $<0.001$ \\
\hline \multicolumn{5}{|l|}{ Complication } \\
\hline Sepsis (\%) & $104(85.2)$ & $25(78.1)$ & $79(87.8)$ & 0.245 \\
\hline Septic Shock(\%) & $74(60.7)$ & $19(59.4)$ & $55(61.1)$ & 0.863 \\
\hline PCP (\%) & $71(58.2)$ & $12(37.5)$ & $59(65.6)$ & 0.006 \\
\hline Respiratory Failure (\%) & $81(66.4)$ & $15(46.9)$ & $65(72.2)$ & 0.01 \\
\hline \multicolumn{5}{|l|}{ Multiple Organs Support Therapy } \\
\hline The use of vasoactive agents (\%) & $81(66.4)$ & $22(68.8)$ & $59(65.6)$ & 0.742 \\
\hline Duration of Mechanical ventilation (h) & $131.5(16-264)$ & $141.5(5-225.5)$ & $124.5(24-264.0)$ & 0.788 \\
\hline \multicolumn{5}{|l|}{ Severity of illness } \\
\hline SOFA score at ICU admission & $8(4-12)$ & $12(6-16)$ & $7(4-10)$ & $<0.001$ \\
\hline APACHE-II score at ICU admission & $20(15-28)$ & $28(21-34)$ & $18(15-23)$ & $<0.001$ \\
\hline \multicolumn{5}{|l|}{ Outcome } \\
\hline Death during in ICU & $61(50)$ & $18(56.3)$ & $43(47.8)$ & 0.41 \\
\hline Length of ICU stay (days), median (IQR) & $9(5-16)$ & $8(5-16)$ & $9(5-17)$ & 0.616 \\
\hline Length of hospital stay (days), median (IQR) & $17(9-30)$ & $15(7-21)$ & $20(10-34)$ & 0.022 \\
\hline
\end{tabular}

ICU Intensive care unit, HIV Human immunodeficiency virus, HAART Highly Active Anti-Retroviral Therapy, PCP Pneumocystis carinii pneumonia, CRRT Continuous renal replacement therapy, SOFA, IQR Interquartile range, APACHE-II Acute physiology and chronic health evaluation, version II, SOFA Sequential organ failure assessment, GFR Glomerular Filtration Rate, MPV Mean Platelet Volume

$p$ Value $<0.05$ was considered significant and is highlighted in bold

respiratory failure, septic shock, the use of vasoactive agents, duration of mechanical ventilation, diagnosis of PCP, SOFA score at ICU admission were independent risk factors for CRRT by univariate logistics analysis.

Higher likelihood of diagnosis for respiratory failure $(\mathrm{OR}=7.333,95 \% \mathrm{CI} 1.467-36.664, p=0.015)$, higher likelihood of diagnosis for septic shock $(\mathrm{OR}=1.005,95 \% \mathrm{CI}$ $1.001-1.01, p=0.018)$, and higher likelihood to use vasoactive agents $(\mathrm{OR}=10.667,95 \%$ CI 1.743-65.271, $p=$ $0.001)$, longer mechanical ventilation duration $(\mathrm{OR}=$ $1.011,95 \%$ CI 1.002-1.019, $p=0.011)$, higher likelihood for diagnosis for PCP (OR $=7.50,95 \%$ CI 1.288-43.687, $p=0.025)$, higher SOFA score at ICU admission (OR = $1.183,95 \%$ CI 1.012-1.383, $p=0.035$ ), longer duration of CRRT (OR $=1.014,95 \%$ CI 1.001-1.028, $p=0.034)$ contributed to a higher mortality at ICU.

As shown in Fig. 1, Among the AKI stage 3 patients, about a half received CRRT during their stay at ICU. Then we compared the two groups shown in Table 3 . Plasma-albumin and CD4 counts at ICU admission had a statistically significant difference $(p=0.027$ and $p=$ 0.009 , respectively). In severity of illness, patients who received CRRT had a higher APACHE-II scores ( $p=$ 0.015). Even with CRRT, the main outcome, such as the 


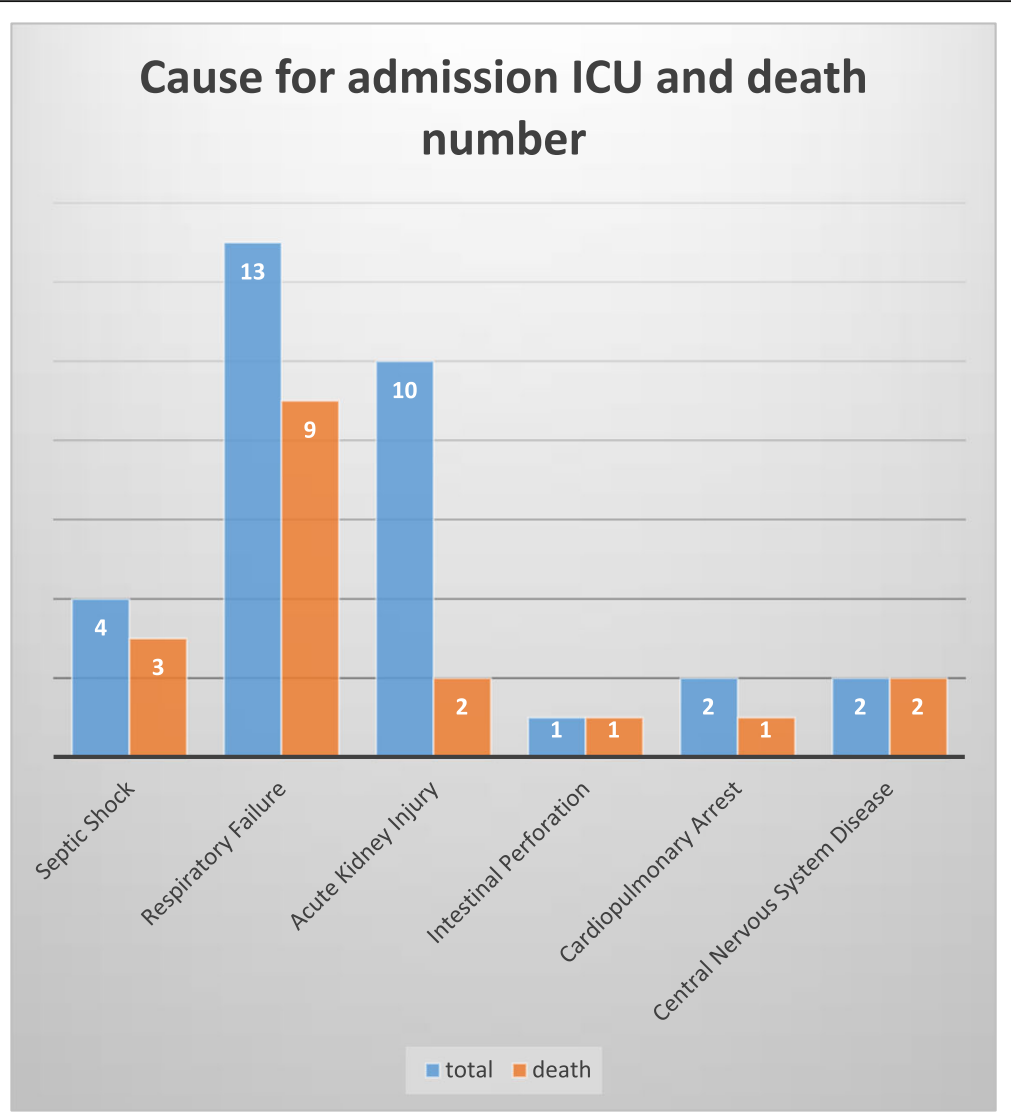

Fig. 2 Cause for admission ICU and death number of the 32 CRRT patients

mortality at ICU, and the renal recovery in the two groups did not show a significant difference $(p=0.521$ and $p=0.353$, respectively). Patients who received CRRT probably had a longer stay tendency at ICU $(p=0.679)$, but a shorter hospital stay $(p=0.029)$.

As shown by the cumulative survival curves of HIVinfected patients who were diagnosed with AKI 3 admitted to the intensive care unit (Fig. 3), the group of CRRT and non-CRRT had no significant difference $(p=0.595)$. As determined by the Cox Analysis of the cumulative survival of 3 AKI patients between the CRRT and non-
CRRT groups (Table 4), the possibility of using vasoactive agents shows a significant difference on AKI stage 3 patients' survival $(p=0.015, \quad \mathrm{OR}=12.621,95 \% \quad \mathrm{CI}$ 1.637-97.293).

\section{Discussion}

Lin $\mathrm{Pu}$ has concluded that AKI occurred more than 50\% on HIV-infected patients admitted to the ICU [10]. Consistent with previous reports: the incidence of AKI for the patients admitted at ICU is $67 \%$ [10].CRRT has practically and efficiently used in patients with AKI as a basic

Table 2 Univariate Analysis for the Identification of Predictors the Death of CRRT in ICU

\begin{tabular}{llll}
\hline & Odds ratio & $95 \%$ Confidence interval & \\
\hline Respiratory Failure & 7.333 & $1.467-36.664$ & $\mathbf{0 . 0 1 5}$ \\
Septic Shock & 1.005 & $1.001-1.010$ & $\mathbf{0 . 0 1 8}$ \\
The use of vasoactive agents & 10.667 & $1.743-65.271$ & $\mathbf{0 . 0 0 1}$ \\
Duration of Mechanical Ventilation & 1.011 & $1.002-1.019$ & $\mathbf{0 . 0 1 1}$ \\
PCP & 7.50 & $1.288-43.687$ & $\mathbf{0 . 0 2 5}$ \\
SOFA score at ICU admission & 1.183 & $1.012-1.383$ & $\mathbf{0 . 0 3 5}$ \\
Duration of CRRT & 1.014 & $1.001-1.028$ & $\mathbf{0 . 0 3 4}$
\end{tabular}

CRRT Continuous renal replacement therapy, ICU Intensive care medicine, SOFA Sequential organ failure assessment, $P C P$ Pneumocystis carinii pneumonia $p$ Value $<0.05$ was considered significant and is highlighted in bold 
Table 3 The comparison between Patients with CRRT and non-CRRT who were in AKI stage 3

\begin{tabular}{|c|c|c|c|c|}
\hline & AKI stage $3(N=63)$ & CRRT $(N=32)$ & non-CRRT $(N=31)$ & $p$ \\
\hline Male(\%) & $57(90.5)$ & $31(96.9)$ & $26(83.9)$ & 0.104 \\
\hline Age(years) & $43(37-50)$ & $42(37-56)$ & $44(36-48)$ & 0.527 \\
\hline \multicolumn{5}{|l|}{ Blood routine and biochemical items } \\
\hline Lymphocyte count $\left(\times 10^{9}\right)$ & $0.5(0.24-1.00)$ & $0.54(0.34-1.05)$ & $0.5(0.2-0.8)$ & 0.146 \\
\hline Hemoglobin(g/L) & $91(70.8-108)$ & $91(71.8-109.5)$ & $89(70.7-104.5)$ & 0.929 \\
\hline Albumin(g/L) & $27.4(23.8-31.7)$ & $30.3(24.9-32.5)$ & $26.8(22.3-30.2)$ & 0.027 \\
\hline T-Bil (umol/L) & $8.7(5.8-15.9)$ & $7.8(5.1-14.5)$ & $11.4(6.3-16.0)$ & 0.343 \\
\hline Serum calcium(mmol/L) & $1.92(1.71-2.09)$ & $2.0(1.68-2.18)$ & $1.88(1.74-2.03)$ & 0.221 \\
\hline Lactate $(\mathrm{mmol} / \mathrm{L})$ & $2.8(1.45-6.05)$ & $3.65(1.55-7.15)$ & $2.1(1.35-5.0)$ & 0.091 \\
\hline Serum phosphate(mmol/L) & $1.11(0.81-1.65)$ & $1.45(0.81-1.88)$ & $1.02(0.81-1.36)$ & 0.159 \\
\hline $\mathrm{LDH}(\mathrm{U} / \mathrm{L})$ & $450(309.6-786.6)$ & $501(281.6-1233)$ & $450(321.2-663.2)$ & 0.336 \\
\hline \multicolumn{5}{|l|}{ Items related to HIV infection } \\
\hline CD4 counts at ICU admission(cells/ml) & $24(8-86)$ & $37(13-116)$ & $11(5-36)$ & 0.009 \\
\hline HIV viral load (copies/mL) & $1700(90-249,112)$ & $1650(0-174,710)$ & $37,444(1142-335,614)$ & 0.116 \\
\hline HAART(\%) & $26(41)$ & $10(31)$ & $16(51.6)$ & 0.052 \\
\hline \multicolumn{5}{|l|}{ Complication } \\
\hline PCP (\%) & $30(47.6)$ & $12(37.5)$ & $18(58.1)$ & 0.102 \\
\hline Septic Shock(\%) & $41(65.1)$ & $19(59.4)$ & $22(71)$ & 0.245 \\
\hline \multicolumn{5}{|l|}{ Multiple Organs Support Therapy } \\
\hline The use of vasoactive agents(\%) & $46(73)$ & $22(66.8)$ & $24(77.4)$ & 0.349 \\
\hline Duration of Mechanical ventilation (h) & $120(7-240)$ & $142(5-256)$ & $119(14-212.5)$ & 0.825 \\
\hline \multicolumn{5}{|l|}{ Severity of illness } \\
\hline SOFA score at ICU admission (scores) & $9(7-13)$ & $11(7-14)$ & $9(6-11)$ & 0.094 \\
\hline APACHE-II score at ICU admission(scores) & $23(19-33)$ & $28(22-35)$ & $19(18-30)$ & 0.015 \\
\hline \multicolumn{5}{|l|}{ Outcome } \\
\hline Death during in ICU & $34(54)$ & $18(56)$ & $14(45.2)$ & 0.521 \\
\hline Renal recovery & $17(27.0)$ & $7(21.9)$ & $10(32.3)$ & 0.353 \\
\hline Length of ICU stay (days), median (IQR) & $8(5-14)$ & $8(5-15)$ & $6(5-14)$ & 0.679 \\
\hline Length of hospital (days), median (IQR) & $16(9-29)$ & $15(7-21)$ & $17(12-38)$ & 0.029 \\
\hline
\end{tabular}

T-Bil Total bilirubin, HAART Highly Active Anti-Retroviral Therapy, PCP Pneumocystis carinii pneumonia, CRRT Continuous renal replacement therapy, ICU Intensive care unit, IQR Interquartile range, APACHE-II Acute physiology and chronic health evaluation, version II, SOFA Sequential organ failure assessment $p$ Value $<0.05$ was considered significant and is highlighted in bold

equipment $[5,11]$. But the occurrence rate and influencing factors to predict patients' death of CRRT in ICU among the Chinese population is still unclear.

26.2\% patients with AKI received CRRT during their stay at ICU in this study, at a significantly higher proportion than 5-6\% patients without HIV [2]. The result indicated that HIV-infected patients were more prone to develop severe AKI. Patients with HIV lost kidney function faster than the overall population [12, 13]. Exposure to nephrotoxic drugs such as tenofovir and HIV replicating in other cells besides CD4 cells may aggravate deterioration of the renal function [14-16]. Rasch et al. found that the possibility of HIV patients receiving RRT were more than 4-fold compared with the overall population without RRT. Age, hypertension and AIDS were associated with an increased risk of RRT [14].

There is no difference with a previous study: the mortality ranging from 37 to $88 \%$ for the patients admitted at ICU who needed the RRT [17]. The study indicated that $56.25 \%$ of CRRT patients died at ICU. Mortality was higher in patients with HIV/AIDS, most likely due to the serious immunosuppression and opportunistic diseases [18]. Compared with survivals with CRRT, 15 nonsurvived patients suffered from septic shock during their stay at ICU.

Death of patients at ICU was more frequent of they were diagnosed with septic shock, PCP, or had a longer duration of CRRT. Ling ping et al. reported that sepsis- 


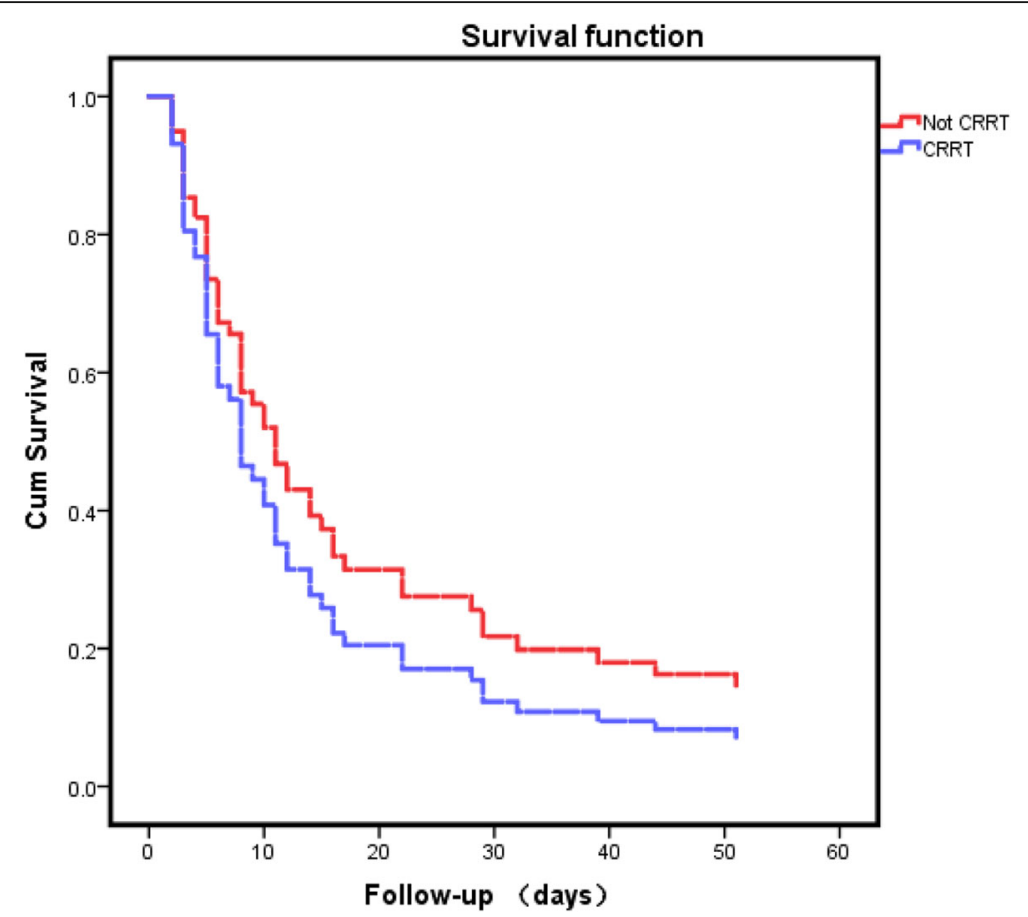

Fig. 3 Cumulative survival curves of HIV infected patients who were diagnosed with AKI 3 admitted to the intensive care unit, received CRRT or not received (two groups)

related AKI and using vasopressors were independent risk factors to increase patients' mortality [19]. Dopamine and norepinephrine are two types of common vasopressors widely used in curing different types of shocks. Patients with septic shock are usually affected by hypotension and coagulopathy [20]. Multiple organ syndrome occurred as a result of ischemia reperfusion injury. Use of vasoactive agents using might increase the risk of ICU death by the poor cardiovascular response to the catecholamine. Chou et al. reported that critically ill patients being treated with a high dose of vasopressor also had a higher ICU mortality, with CRRT not improving patients' prognosis [21].

Patients with HIV infection are more vulnerable to be affected by opportunistic infections. PCP has been a common manifestation during HIV infection in developed countries. It played an important role throughout the course of the disease and often as the initial manifestation of acquired immunodeficiency syndrome (AIDS) [22]. Meanwhile it resulted in lung injury and gas exchange by inducing a pulmonary inflammatory response. Tumor necrosis factor- $\alpha$ and other immunomodulatory molecules were released as a response to the infection [23, 24]. Prasad et al. found that patients with a higher $\mathrm{FiO} 2$ requirements while ventilated and a higher vasoactive agent administration were inclined to have an early (within $24 \mathrm{~h}$ ) mortality [25]. PCP prophylaxis has been widely used in developed countries [22], but still not commonly used in developing countries. No patients received PCP prophylaxis in this study. On the other hand, $25-33 \%$ patients were not diagnosed of PCP before they were clearly diagnosed of HIV [26]. Early diagnosis of HIV-infection and PCP prophylaxis perhaps contributed to a decreased mortality of CRRT.

This study suggests that a longer duration of CRRT can contribute to patients' death at ICU. Longer duration of

Table 4 The Cox Analysis for the cumulative survival of AKI 3 patients between the CRRT and non-CRRT groups

\begin{tabular}{llll}
\hline & Odds ratio & $95 \%$ Confidence interval & $p$ \\
\hline CRRT & 1.236 & $0.566-2.70$ & 0.595 \\
The possibility of using vasoactive agents & 12.621 & $1.637-97.293$ & $\mathbf{0 . 0 1 5}$ \\
SOFA score at ICU admission & 0.978 & $0.896-1.068$ & 0.625 \\
PCP & 0.831 & $0.362-1.909$ & 0.663 \\
\hline
\end{tabular}

CRRT Continuous renal replacement therapy, ICU Intensive care unit, SOFA Sequential organ failure assessment, $P C P$ Pneumocystis carinii pneumonia $p$ Value $<0.05$ was considered significant and is highlighted in bold 
CRRT can increase the likelihood of a catheter related bloodstream infection (CRSBI) and more vulnerability of CRRT related complications. Scott found that there was no difference of pediatric survival rate between long and short duration of CRRT [27]. The longer duration of CRRT, the higher risk of complications the patients might have. The patients enrolled in this study were all immunodeficient, therefore any opportunistic infection can be fatal for them.

The 28-day mortality of patients with CRRT was $62.5 \%$ in this study, matching with the $62 \%$ found in sepsis-induced acute kidney injury patients undergoing CRRT in previous reports [28].

As shown in Fig. 2, 13 patients with a respiratory failure represent the highest proportion of the ICU admission, $10(76.9 \%)$ patients died at ICU. Ten patients of AKI represent the second group of ICU admission, only $2(20 \%)$ died at ICU. Three patients accepted the treatment at ICU because of septic shock, 3 of total (75\%) did not survive at ICU. The figure indicated that patients who were initially diagnosed with AKI had probably a better prognosis. On the contrary, the patients who were initially admitted at ICU for respiratory failure or septic shock, usually had a poor outcome compared to patients diagnosed with AKI and needed the help of CRRT.

With the extensively use of highly active antiretroviral therapy (HAART), the survival of HIV-infected patients have been significantly improved [29]. The use of antiretroviral drugs is another determinant factor to compromise the renal function and increase the risk for CRRT [30]. Previous studies indicated that both HIV infection and HAART were directly nephrotoxic [31-34]. We also confirmed that only 30 (24.6\%) patients with AKI received the HAART during their stay at ICU, there was no significant difference between the CRRT group and the non-CRRT group. The reason why most patients never received the HAART was that $71.1 \%$ patients were diagnosed with HIV infection within 3 months, so the treatment was not started yet [35].

The count of CD4+ cells reflects the immune status of HIV-infected patients. A previous study has proven that CD4 count $<200$ cells/ml was an independent predictor of experiencing AKI [36]. Low CD4 count and AIDS are risk factors for HIV-infected people suffering from AKI [37]. Lower CD4 count made HIV patients more vulnerable to suffer from opportunistic infections and increased the risk of kidney injury [35]. The average CD4 count of AKI patients was $23(8-78)$ cells $/ \mathrm{ml}$, and there was a statistically significant difference $(p=0.043)$ between the CRRT group $37(13-122)$ cells $/ \mathrm{ml}$ and the non-CRRT group $15(7-69)$ cells $/ \mathrm{ml}$. But there was no significant difference $(p=0.464)$ between the CRRT survival group $97(25-156)$ cells/ml and the CRRT nonsurvival group $40(15-110)$ cells/ml. CD4 count $<200$ cells $/ \mathrm{ml}$ can lead to immune depression, however, there was no significant difference $(p=0.245$ and $p=0.863)$ between the CRRT group and the non-CRRT group for sepsis and septic shock. The reason why there was no significant difference between the two groups on CD4 count is probably because the patients admitted at ICU were both suffering for severe immunosuppression and easier to be infected by different pathogens. Franceschini et al. concluded that with the decreasing of patients' CD4 count, the possibility of morbidity and mortality extensively increased [36].

By using the Cox Analysis for the cumulative survival of AKI 3 patients between the CRRT and non-CRRT groups in Fig. 3, we conclude that CRRT did not improve patients' long-term survival $(p=0.595)$. Most likely, CRRT had a determinant effect in maintaining the stability of the internal environment and decreasing pre load of heart. While CRRT was a maintenance intervention, other critical conditions except renal injury might affect the outcome. But as the cumulative survival curves illustrated in Fig. 3, APACHE-II score at ICU admission of CRRT and non-CRRT group were separated 28(2235) and 19(18-30), $p=0.015$. Data in the Fig. 3 indicated that patients in the CRRT group were more critical. The cumulative survival rate of the CRRT group was lower than the one in the non-CRRT group. The result indicated that AKI 3 might be not the proper stage to start an active intervention. Patients might benefit from an earlier intervention at AKI stage 1 or AKI stage 2.

\section{Limitations}

The number of CRRT events is relatively small, which limits statistical power of analyses. This is a retrospective study. Thus, a large, prospective, randomized, controlled study is needed. Further investigations on different modes and therapeutic dose should be conducted.

\section{Conclusions}

There is a high incidence of AKI in HIV-infected patients admitted in our ICU. Patients with severe AKI were more prone to be admitted for CRRT and have a consequent poor prognosis.

\begin{abstract}
Abbreviations
AKI: Acute kidney injury; APACHE-II: Acute physiology and chronic health evaluation, version II; CRRT: Continuous renal replacement therapy; GFR: Glomerular Filtration Rate; HAART: Highly Active Anti-Retroviral Therapy; HIV: Human immunodeficiency virus; ICU: Intensive care unit;

IQR: Interquartile range; MPV: Mean Platelet Volume; PCP: Pneumocystis carinii pneumonia; SOFA: Sequential organ failure assessment; T-Bil: Total bilirubin
\end{abstract}

Acknowledgements

Not applicable.

Authors' contributions

$A L$ and $J Y L$ designed the research study and provided research ideas. LP, $J J H, N N Y, Y F L, H F X$ read the literature and collected medical records. HBG 
was a major contributor in writing the manuscript. The authors read and approved the final manuscript.

\section{Funding}

This work was supported, in part, by funding from the Sail Plan program of Beijing Municipal Administration of Hospitals (ZYLX201802). The design of the study and collection of data in this research were funded by the program.

\section{Availability of data and materials}

The data generated and analyzed during the current study are available from the corresponding author on reasonable request.

\section{Ethics approval and consent to participate}

Because no trial of any specific therapeutic or prophylactic intervention was carried out, and only observational data were used for our analysis, an informed consent to participate for this study was not required according to our institution's guidelines.

This study was approved by the Ethics Committee of Beijing Ditan Hospital, Capital Medical University, No.2018-005-01.

\section{Consent for publication}

Not applicable.

\section{Competing interests}

The authors declare that they have no competing interests.

Received: 17 December 2019 Accepted: 28 February 2020

Published online: 11 March 2020

\section{References}

1. Lameire NH, Bagga A, Cruz D, De MJ, Endre Z, Kellum JA, et al. Acute kidney injury: an increasing global concern. Lancet. 2013;382(9887):170-9.

2. Shigehiko U, Kellum JA, Rinaldo B, Doig GS, Hiroshi M, Stanislao M, et al. Acute renal failure in critically ill patients: a multinational, multicenter study. JAMA. 2005;294(7):813-8.

3. Cohen SD, Chawla LS, Kimmel PL. Acute kidney injury in patients with human immunodeficiency virus infection. Curr Opin Crit Care. 2008;14(6): 647-53

4. Randall D, Brima N, Walker D, Connolly J, Laing C, Copas A, et al. Acute kidney injury among HIV-infected patients admitted to the intensive care unit. Int J STD AIDS. 2014;26(13):915.

5. Allegretti AS, Steele DJR, Jo Ann DK, Ednan B, Niles JL, Ishir B. Continuous renal replacement therapy outcomes in acute kidney injury and end-stage renal disease: a cohort study. Crit Care. 2013;17(3):R109.

6. Lins RL, Elseviers MM, Niepen PVD, Hoste E, Malbrain ML, Damas P, et al. Intermittent versus continuous renal replacement therapy for acute kidney injury patients admitted to the intensive care unit: results of a randomized clinical trial. Nephrol Dial Transplant. 2009;24(2):512-8.

7. Arif K. KDIGO clinical practice guidelines for acute kidney injury. Nephron Clin Pract. 2012;120(4):179-84.

8. Branson BM, Mermin J. Establishing the diagnosis of HIV infection: new tests and a new algorithm for the United States. J Clin Virol. 2011;52(52 Suppl 1): S3-4.

9. Home C. Revised surveillance case definition for HIV infection--United States, 2014. MMWR Recomm Rep. 2014;63(RR-03):1-10.

10. Hoste EA, Clermont G, Kersten A, Venkataraman R, Angus DC, Bacquer DD, et al. RIFLE criteria for acute kidney injury are associated with hospital mortality in critically ill patients: a cohort analysis. Critical Care,10,3(2006-0512). 2006;10(3):R73

11. Cappi SB, Sakr Y, Vincent JL. Daily evaluation of organ function during renal replacement therapy in intensive care unit patients with acute renal failure. J Crit Care. 2006;21(2):179-83.

12. Rasch MG, Engsig FN, Feldt-Rasmussen B, Kirk O, Kronborg G, Pedersen C, et al. Renal function and incidence of chronic kidney disease in HIV patients: a Danish cohort study. Scand J Infect Dis. 2012;44(9):689.

13. Choi Al, Shlipak MG, Hunt PW. HIV-infected persons continue to lose kidney function despite successful antiretroviral therapy. Aids. 2009;23(16):2143-9.

14. Rasch MG, Marie H, Bo FR, Gitte K, Larsen CS, Court P, et al. Increased risk of dialysis and end-stage renal disease among HIV patients in Denmark compared with the background population. Nephrol Dial Transplant. 2014 29(6):1232-8.
15. Bruggeman LA, Ross MD, Tanji N, Cara A, Dikman S, Gordon RE, et al. Renal epithelium is a previously unrecognized site of HIV-1 infection. J Am Soc Nephrol. 2000;11(11):2079-87.

16. Sonia RN, Elena A, Pablo L, Vincent S. Renal toxicity associated with tenofovir use. Expert Opin Drug Saf. 2010;9(4):545.

17. Bellomo R, Ronco C, Kellum JA, Mehta RL, Palevsky P, Workgroup TA. Acute renal failure - definition, outcome measures, animal models, fluid therapy and information technology needs: the second international consensus conference of the acute dialysis quality initiative (ADQI) group. Crit Care. 2004;8(4):R204-12.

18. Daher EDF, Silva GBD, Vieira APF Jr, Souza JBD, Falcão FDS, Costa CRD, et al. Acute kidney injury in a tropical country: a cohort study of 253 patients in an infectious diseases intensive care unit. Rev Soc Bras Med Trop. 2014; 47(1):86-9.

19. Wu L, Zhang $P$, Yang $Y$, Jiang $H, H e ~ Y, X u C$, et al. Long-term renal and overall survival of critically ill patients with acute renal injury who received continuous renal replacement therapy. Ren Fail. 2017;39(1):736-44.

20. Shum HP, Chan KC, Kwan MC, Yeung WT, Cheung WS, Yan WW. Timing for initiation of continuous renal replacement therapy in patients with septic shock and acute kidney injury. Crit Care. 2013;17(6):643.

21. Che-Yi C, Hung-Chieh Y, Wei C, Jiung-Hsiun L, Hsin-Hung L, Yao-Lung L, et al. Norepinephrine and hospital mortality in critically ill patients undergoing continuous renal replacement therapy. Artif Organs. 2015;35(2): E11-7.

22. Siegel M, Masur H, Kovacs J. Pneumocystis jirovecii pneumonia in human immunodeficiency virus infection. Semin Respir Crit Care Med. 2016;37(02): 243-56.

23. Vassallo R, Standing J, Limper AH. Isolated pneumocystis carinii cell wall glucan provokes lower respiratory tract inflammatory responses. J Immunol. 2000;164(7):3755-63.

24. Thomas CF, Limper AH. Pneumocystis pneumonia. N Engl J Med. 2004; 350(24):2487-98.

25. Prasad B, Urbanski M, Ferguson TW, Karreman E, Tangri N. Early mortality on continuous renal replacement therapy (CRRT): the prairie CRRT study. Can J Kidney Health Dis. 2016;3(1):36.

26. Llibre JM, Boris R, Samuel V, Lopez-Nuñez JJ, Arelly O, Marin JM, et al. Pneumocystis jirovecii pneumonia in HIV-1-infected patients in the lateHAART era in developed countries. Scand J Infect Dis. 2013;45(8):635-44

27. J Scott B, Wald EL. Long-duration ( $>4$ weeks) continuous renal replacement therapy in critical illness. Int J Artif Organs. 2010;33(10):716.

28. Cho AY, Yoon HJ, Lee KY, Sun IO. Clinical characteristics of sepsis-induced acute kidney injury in patients undergoing continuous renal replacement therapy. Ren Fail. 2018;40(1):403-9.

29. Kalim S, Szczech LA, Wyatt CM. Acute kidney injury in HIV-infected patients. Semin Nephrol. 2008;28(6):556-62.

30. Wyatt CM, Klotman PE. HIV-associated nephropathy in the era of antiretroviral therapy. Am J Med. 2007;120(6):488-92.

31. Wyatt CM, Arons RR, Klotman PE, Klotman ME. Acute renal failure in hospitalized patients with HIV: risk factors and impact on in-hospital mortality. Aids. 2006;20(4):561-5.

32. Choi Al, Li Y, Parikh C, Volberding PA, Shlipak MG. Long-term clinical consequences of acute kidney injury in the HIV-infected. Kidney Int. 2010; 78(5):478-85.

33. Islam FM. Relative risk of renal disease among people living with HIV: a systematic review and meta-analysis. BMC Public Health. 2012;12(1):234

34. Izzedine $H$, Baumelou A, Deray G. Acute renal failure in HIV patients. Nephrol Dial Transplantation. 2007;22(10):2757-62.

35. Lin $P$, Jingyuan $L$, Yang $L$, Hui $Z$, Hebing $G$, Jingjing $H$, Ningning $Y$, Yufeng $L$, Haofeng X, Jian X. Acute kidney injury in chinese HIV-infected patients: a retrospective analysis from the intensive care unit. AIDS Patient Care STDS 2018:32(10):381-9.

36. Franceschini N, Napravnik S, Eron JJ, Szczech LA, Finn WF. Incidence and etiology of acute renal failure among ambulatory HIV-infected patients. Kidney Int. 2005;67(4):1526.

37. Vachiat Al, Musenge E, Wadee S, Naicker S. Renal failure in HIV-positive patients_a south African experience. CKJ Clin Kidney J. 2013;6(6):584-9.

\section{Publisher's Note}

Springer Nature remains neutral with regard to jurisdictional claims in published maps and institutional affiliations. 